University of Nebraska - Lincoln

DigitalCommons@University of Nebraska - Lincoln

October 1997

\title{
THE EFFECTS OF DIVORCE AND CUSTODY ARRANGEMENTS ON CHILDREN'S BEHAVIOR, DEVELOPMENT, AND ADJUSTMENT
}

\author{
Michael E. Lamb \\ National Institute of Child Health and Human Development in Bethesda, MD \\ Kathleen J. Sternberg \\ National Institute of Child Health and Human Development in Bethesda, MD \\ Ross A. Thompson \\ University of Nebraska-Lincoln, rthompson1@unl.edu
}

Follow this and additional works at: https://digitalcommons.unl.edu/psychfacpub

Part of the Psychiatry and Psychology Commons

Lamb, Michael E.; Sternberg, Kathleen J.; and Thompson, Ross A., "THE EFFECTS OF DIVORCE AND CUSTODY ARRANGEMENTS ON CHILDREN'S BEHAVIOR, DEVELOPMENT, AND ADJUSTMENT" (1997). Faculty Publications, Department of Psychology. 334.

https://digitalcommons.unl.edu/psychfacpub/334

This Article is brought to you for free and open access by the Psychology, Department of at DigitalCommons@University of Nebraska - Lincoln. It has been accepted for inclusion in Faculty Publications, Department of Psychology by an authorized administrator of DigitalCommons@University of Nebraska - Lincoln. 


\title{
THE EFFECTS OF DIVORCE AND CUSTODY ARRANGEMENTS ON CHILDREN'S BEHAVIOR, DEVELOPMENT, AND ADJUSTMENT
}

\author{
Michael E. Lamb, Kathleen J. Sternberg, and Ross A. Thompson
}

\begin{abstract}
This article summarizes the consensus among a group of experts from developmental and clinical psychology, sociology, social welfare, and law who sought to evaluate existing empirical evidence regarding the ways in which children are affected by divorce and the varying custody arrangements that follow it. Divorce and/or single parenthood tend to have adverse effects on children's adjustment, with the magnitude of the effects varying depending on the psychological status of the two parents, the extent of conflict between them, and the financial circumstances, particularly after divorce. Children whose nonresidential parents continue to support them financially, those whose custodial parents are psychologically healthy, and those who have and maintain meaningful relationships with nonresidential parents tend to be affected less by the divorce, especially when there is no conflict between the parents. Interventions should thus be designed with these factors in mind.
\end{abstract}

A group of experts from developmental and clinical psychology, sociology, social welfare, and law met at a conference center in Middleburg, Virginia, on December 1-4, 1994, under the sponsorship of the U.S. National Institute of Child Health and Human Development. The group's mandate was to evaluate existing knowledge regarding the ways in which children are affected by divorce and the varying custody arrangements that follow it. Many of the discussions also addressed the ways in which the adverse effects of divorce might be ameliorated by changes in policy or practice. This document represents a statement cosigned by most of the participants, summarizing areas of agreement regarding the current status of knowledge in this area and outlining topics in need of further research. The report is designed to guide various legislatures, the judiciary, the bar, and the various mental health professionals who are involved in counseling or educating families experi-

\footnotetext{
Authors' Note: This article was written on behalf of Paul Amato, David L. Chambers, Gary Crippen, E. Mark Cummings, Robert Emery, Phillip W. Esplin, Irwin Garfinkel, Kathleen Gilbride, E. Mavis Hetherington, Guillermina Jasso, Janet Johnston, Joan B. Kelly, Sarah McLanahan, Joyce Thomas, and Nicholas Zill. We would like to thank the other participants for their help.
} 
encing separation or divorce, as well as those who mediate or adjudicate the disputes regarding the custody of minor children. The preliminary draft of this consensus document was prepared by Michael E. Lamb and Kathleen J. Sternberg following the 3-day conference, with additional redrafting by Ross A. Thompson. The draft was reviewed and revised by the other participants over the ensuing months. This report, revised in accordance with the participants' comments, is a product of this process.

A primary purpose of this document is to summarize the relevant empirical data and clear away much of the contention that obscures substantial areas of agreement concerning the effects of divorce, custody, and visitation. Because it represents the consensus of a number of scholars and practitioners from a variety of backgrounds, this document focuses on broad areas of agreement rather than on areas of continuing uncertainty or disagreement, although the latter are also identified. To facilitate our presentation and avoid debate over which aspects of individual reports should be emphasized, we have avoided explicit references to the scholarly literature in this document.

\section{THE PROBLEM}

Concerns about the risks associated with divorce and/or single parenthood have been enhanced by the high rate of divorce in many industrialized countries. In the United States, about $45 \%$ of all first marriages are now dissolved, and in the United Kingdom, $41 \%$ divorce within 14 years. This statement is focused on the development and well-being of children who began life in two-parent unions and who thus experience significant disruptions in their relationships with their parents during childhood as a result of divorce. We can only speculate about the relevance of this document to the experience of children born to single mothers, who are also a rapidly expanding proportion of children in the United States and other countries.

Insight into the consequences of divorce for children can be gleaned from considering its immediate effects on all the individuals involved. Most family members experience substantial psychological and emotional disturbance around the time of divorce, although this is sometimes mixed with more positive feelings, especially when there is relief regarding the resolution of the problems leading to divorce. Whatever the antecedents, family dissolution is clearly disruptive for mothers, fathers, and children, most of whom experience varying degrees of distress, depression, loneliness, regret, lack of control, helplessness, and anger. These psychological symptoms are not simply acute responses to immediate stress. For many families, symptoms are still at peak levels a year or two after the separation, and there is wide 
variability in the length of time most individuals take to achieve a new equilibrium. Preoccupation with their own emotional turmoil clearly limits parents' abilities to support their children emotionally and enforce consistent expectations and demands. This is true of both nonresidential (noncustodial) and residential parents, and not surprisingly, the overall psychological and economic well-being of residential parents often ranks as one of the most powerful predictors of children's adjustment following divorce.

Divorce is also associated with the relocation of at least one and often all family members. This may exacerbate stress and increases the risk of social isolation for all concerned by limiting the ability of friends and relatives to provide the social and emotional support needed during these stressful times, although it may sometimes involve increased support for those who move closer to their families of origin. The establishment and maintenance of two separate residences also impose economic burdens that are unequally experienced by the separating parents. These burdens are typically greatest for women because of their poorer wage-earning opportunities and because they are usually responsible for most postdivorce child care responsibilities: The vast majority of the children affected by divorce reside primarily in their mothers' households. At least initially, furthermore, the economic circumstances of most, although not all, divorced fathers tend to improve while those of divorced mothers and their children decline before stabilizing below predivorce levels. Economic factors thus add significantly to the forces that make divorce and separation harmful to the development and psychological well-being of the children involved. Remarriage often has economic benefits for single parents and their children, but it also entails further adjustment to stepparents and stepsiblings. Although children's adjustment to blended families has been studied relatively little, we know that readjustment can be stressful. On the other hand, remarriage often restores mothers' economic circumstances to their predivorce status because of the supplemental income provided by stepfathers, and relationships with stepparents can provide emotional support to children and to the remarrying parents.

Overall, most children of divorce experience dramatic declines in their economic circumstances, abandonment (or the fear of abandonment) by one or both of their parents, the diminished capacity of both parents to attend meaningfully and constructively to their children's needs (because they are preoccupied with their own psychological, social, and economic distress as well as stresses related to the legal divorce), and diminished contact with many familiar or potential sources of psychosocial support (friends, neighbors, teachers, schoolmates, etc.), as well as familiar living settings. As a consequence, the experience of divorce is a psychosocial stressor and a significant life transition for most children, with long-term repercussions for 
many. Some children from divorced homes show long-term behavior problems, depression, poor school performance, acting out, low self-esteem, and (in adolescence and young adulthood) difficulties with intimate heterosexual relationships.

Although divorce is a painful experience that increases children's psychosocial vulnerability, the long-term effects of divorce should not be exaggerated. Despite the significant and troubling risks of maladjustment among children whose parents divorce, the majority of children in these circumstances appear, in the long run, to be developing within the normal rangewithout identifiable psychosocial scars or other adverse consequences-even when the process of marital dissolution was painful for them. In addition, divorce may offer members of dysfunctional families the opportunity to escape from family stress and conflict.

When ex-spouses are able to work through their anger, disappointment, and loss in a timely manner and can establish healthy interpersonal relationships with other adults, divorces can be considered successful. Fortunately, the majority of divorcing adults are able to achieve this status, although one fourth to one third have considerable difficulty, and $5 \%$ and $10 \%$ clearly fail to attain this goal. The latter remain embittered and actively hostile for many years, and this places their children at a considerably higher risk of psychosocial problems. These high-conflict parents and couples are identified with multiple characteristics: high rates of litigation and relitigation, high degrees of anger and distrust, intermittent verbal and/or physical aggression, difficulty focusing on their children's needs as distinct from their own, and chronic difficulty coparenting and communicating about their children after divorce. Their interparental struggle assumes center stage and, as a consequence, children's personal circumstances and developmental needs are often given inadequate attention.

Because of the persistence of high divorce rates for several decades, this accumulating subgroup of high-conflict divorced couples has come to pose serious problems for society. These families clog the family courts, taking more than their share of available resources. Their children are substantially more likely to be clinically disturbed, and they thus consume a disproportionate share of the community's mental health resources as well. When one considers the extent of the stress experienced by most children in these circumstances, it is perhaps remarkable that even more children from highconflict families do not show severe psychopathology. Nevertheless, their enhanced risk of maladjustment is sobering, given the numbers of children involved, and highlights the importance of identifying why some children in comparable circumstances are spared these effects. Although many researchers have studied biological differences in children's vulnerability and 
resilience, it has not yet been possible to identify characteristics that make some individual children intrinsically more resilient in the face of divorce while others are more susceptible to adverse impact. It is also important to note that some children, particularly those who were living in high-conflict or abusive environments, may even manifest improvements in their behavior and mental health following their parents' divorce. Clearly, more research is needed on this topic.

The extent to which children receive economic support from their nonresidential parents is consistently associated with more positive adaptation. Simply put, children whose nonresidential parents continue to support them financially are at lower risk of extended educational disadvantage than those whose nonresidential parents do not pay any child support. There is also a clear association between the payment of child support and the amount of contact between nonresidential parents and their children. The benefits to children's adjustment may thus arise from the economic benefits of child support, a reduction in the level of stress experienced by residential parents, the psychological benefits of maintaining relationships with nonresidential parents, or some combination of these interrelated factors.

Unfortunately, the majority of nonresidential fathers fail to maintain or are prevented from maintaining significant contact with their children during the years following divorce. Declines in the amount of contact between nonresidential parents and their children appear to be, at least in part, attributable to difficulties in visitation arrangements that reduce or eliminate the opportunities for nonresidential parents to be involved in broad areas of their children's lives, making their relationships seem peripheral or artificial. Rather than experiencing the everyday encounters associated with schooling, homework, play, and sports that most parents share with their offspring, nonresidential parents and their children must often create a new visiting relationship that is quite distant from the ordinary experiences of both the children and the adults. This is difficult and, combined with the mutual desires of former spouses to lead independent lives (sometimes in the context of remarriage), may help explain why many nonresidential fathers gradually reduce and eventually abandon visitation altogether.

Most children of divorce want to maintain contact with both parents, and some researchers have shown that the maintenance of an ongoing relationship between nonresidential parents and their children is associated with better adjustment by children. The effects of maintaining contact with both parents are less profound and less consistent than might be expected, however. In part, this seems to reflect the fact that increased contact between nonresidential parents and their children often involves increased and continued contact between the two former spouses. When the relationship between the two 
parents is civil, the benefits of continued contact with each parent are more apparent than when there is substantial conflict between the two. In some circumstances, the level of hostility between the two parents is so high and so recalcitrant that children are harmed rather than helped by frequent contact with each of their parents. Researchers have thus far failed to measure the threshold level of interparental hostility necessary to undermine the benefits to children of continuing contact with both parents and, quite likely, this depends on many factors that are specific to the lives of the parents and children in question. In addition, nonresidential parents who maintain parental roles (providing guidance, discipline, supervision, and educational assistance) may affect their children more profoundly than those who are limited to functioning as occasional visiting companions.

Disagreements are part of any relationship, and exposure to conflict is not necessarily harmful to children. Indeed, exposure to parental conflict can have salutary effects on children when they are able to observe and learn from the constructive resolution of manageable conflict. By contrast, exposure to destructive and unresolved conflict (especially when it is focused on the children) places children at an increased risk of behavioral and psychological maladjustment. Although all divorcing families are not characterized by high levels of conflict before the decision to separate, some degree of conflict commonly occurs during the divorcing process as individuals decide to disengage from each other. Perhaps for this reason, longitudinal studies have shown that the behavior problems of children whose parents have divorced often predated parental separation. It thus becomes important for professionals working with divorcing families to guide disagreements and conflicts toward constructive and explicit resolutions. Such resolutions benefit both the parents themselves and their children.

\section{POLICY CONSIDERATIONS}

Under American family law, married parents are their children's joint legal custodians, with joint and separate authority to make major decisions regarding the fate of their minor children. When marriage ends, shared responsibility for offspring should remain, even though the realities of divorce significantly alter how (and whether) these obligations are exercised or maintained.

In the large majority of postdivorce families, however, mothers assume de jure or de facto primary physical custody of offspring, and fathers usually become increasingly distant figures in their children's lives. This means that the immediate and long-term adjustment of children is closely related to the residential parents' overall well-being and to the quality of the relationship 
between residential parents and their children. The extent to which residential parents are capable of creating and maintaining a satisfactory economic standard of living, can function effectively as single parents, and can reestablish a sense of psychosocial well-being after divorce directly and indirectly benefit the children in their care. As a result, policies that enhance the psychological, social, and financial well-being of residential parents-such as child support enforcement, public income support, and counseling-can be of great importance.

Central to these achievements are the economic conditions of residential parents and their children during the period immediately following the divorce and in the years thereafter. The (sometimes steep) decline in the standard of living of divorced mothers and their children after separation clearly has important implications for the living conditions, educational options, emotional stresses, and other factors associated with the well-being of parents and offspring. Although most children of legally divorced parents receive child support from their nonresidential parents in the United States, the awards have historically covered less than half of the actual costs of raising children, and only half of the nonresidential parents pay the full amount awarded. Recent attempts to increase compliance with child support orders, such as by mandatory wage garnishment, should be associated with improvements in children's adjustment that result from the residential parents' greater economic security, consistent with the research earlier described. It is possible that enhanced child support enforcement might also result in more extensive visitation by nonresidential parents. But because we cannot assume that mandatory compliance with child support orders has the same benefits for child adjustment as does voluntary child support compliance, further research on the correlates and effects of child support enforcement in our rapidly changing social circumstances is clearly necessary.

Even in the context of full compliance, child support awards account for only a fraction of the total incomes of residential parents. For many divorced mothers, obtaining or updating vocational skills, completing educational goals, and finding satisfying and economically rewarding work are among the most significant stresses of immediate and long-term postdivorce life. For some women, a period of reliance on public welfare is an almost inevitable accompaniment of this transition. The importance of an adequate income for residential parents and their offspring thus includes not only satisfactory child support enforcement but also programs that ensure decent minimum incomes (as well as food and medical care, when necessary), the possibility of transitional support from former spouses, and other forms of assistance.

Noneconomic factors, such as the parents' psychological adjustment and the emotional support derived from developing new adult relationships, also 
affect the well-being of residential parents and the quality of the relationships they have with their children. In some cases, furthermore, enhancing the residential parents' well-being and the quality of care they provide involves a complex mixture of economic and noneconomic considerations, such as those involved in residential moves to assume new employment. In our discussions, circumstances such as these presented the most difficult and complex challenges for public policy because of their conflicting implications for children's well-being. On one hand, residential moves are often followed by enhanced standards of living, together with other changes that can benefit residential parents and children alike. On the other hand, such moves also entail the interruption of relationships with peers, extrafamilial care providers, and others on whom children come to rely and the disruption of familiar routines and experiences. Most significantly, they imperil the maintenance of ongoing relationships with nonresidential parents.

Most children in two-parent families form psychologically important and distinctive relationships with both of their parents, even though one may be a primary caretaker. These relationships are not redundant because mothers and fathers each make unique contributions to their children's development and individuality. The majority of children experiencing parental divorce express the desire to maintain relationships with both of their parents after separation. Therefore, in addition to enhancing the psychosocial and economic well-being of residential parents and supporting their relationships with offspring, postdivorce arrangements should also aim to promote the maintenance of relationships between nonresidential parents and their children. The manner in which this occurs can take many forms, depending on individual circumstances such as the relative location of the parents' residences, their work schedules, the ages of the children, the parents' capacities, and the nature of the parents' involvement with the children prior to divorce.

To maintain high-quality relationships with their children, parents need to have sufficiently extensive and regular interaction with them, but the amount of time involved is usually less important than the quality of the interaction that it fosters. Time distribution arrangements that ensure the involvement of both parents in important aspects of their children's everyday lives and routines-including bedtime and waking rituals, transitions to and from school, extracurricular and recreational activities-are likely to keep nonresidential parents playing psychologically important and central roles in the lives of their children. How this is accomplished must be flexibly tailored to the developmental needs, temperament, and changing individual circumstances of the children concerned. Children benefit from regularity, consistency, and continuity, both psychological and geographical. Both before and after divorce, therefore, young children are helped when both of their parents 
have similar daily routines with respect to the children's bedtime, sleeping arrangements, and mealtimes and when there is substantial agreement between parents regarding discipline and basic child-rearing philosophy. Children also benefit when they are able to maintain relationships within the same peer groups, experience care from the same extrafamilial care providers, and attend the same schools. When children have meaningful predivorce relationships with both parents, the psychological continuity achieved by helping them maintain harmonious relationships with both parents after divorce generally, though not always, outweighs the disadvantages arising from transitions between parental homes, provided that attempts are made to reduce other areas of instability and inconsistency. When children do not have meaningful relationships with both parents, by contrast, the relative costs and benefits may be quite different.

Decisions regarding the distribution of time between the two parents are complicated; they involve weighing the potential benefits of maintaining meaningful relationships with both parents against the costs associated with the continuation of those contacts. In light of these considerations, the specific arrangements chosen to promote children's relationships with each of the parents should be clearly articulated in detail to reduce the need for further negotiation, argument, and possible relitigation. Such specification should be sensitive to the inevitable adjustments required as children's needs and circumstances change with age and as their parents' circumstances also change. For example, relocation by either parent might preclude arrangements involving relatively frequent transitions between homes (particularly on school nights), but prior specification in advance of what processes will be used to modify visitation schedules when and if this becomes necessary for either predictable (e.g., age of child) or unexpected reasons can help to make such transitions manageable and less conflictful.

In both intact and divorced households, some parents are clearly unfit to supervise and care for their children because of mental illness or incapacity, serious substance abuse, or because past acts of violent child maltreatment place children at physical or psychological risk. These considerations may outweigh the potential benefits to children of maintaining continuing relationships with such parents. Adults who have a history of chronic spouse abuse or battery also represent threats both to former partners and children. When such histories exist, the potential costs of terminating the children's relationships with their violent parents need to be evaluated thoroughly by trained and impartial professionals whose recommendations concerning the termination of parent-child contact should be made and implemented expeditiously. 
In and of itself, violence toward a spouse or partner does not necessarily indicate that a parent represents a threat to the child's well-being, although it frequently does. Professionals should be especially cautious in their recommendations concerning children whose parents have engaged in mutual or unidirectional acts of violence around the time of divorce but otherwise have a history of nonviolent conflict resolution. Custody and time-sharing plans for children from violent homes need to recognize the merits and characteristics of each case and the quality of the children's relationships with each of their parents.

\section{PUBLIC EDUCATION}

Greater efforts must clearly be made to inform the public, mental health professionals, the bar, and the judiciary regarding the effects of divorce and parental separation on children's well-being and development. More children would surely experience healthy psychosocial growth if fewer children were exposed to divorce in their formative years because their parents better understood the costs to both children and parents relative to the expected benefits of marital dissolution. Certainly, there exist cases in which the mental health, financial security, and even the physical survival of one or more family members depend on marital dissolution, but there are others in which a failure to recognize the prolonged and profound psychological and economic costs leads individuals to seek divorce precipitously and perhaps inappropriately. To date, however, changes in the legally acceptable grounds for divorce are not indicated by the evidence.

Some of the adverse effects of divorce on children might be ameliorated by seeking to minimize the conflict that surrounds the establishment of custody and visitation arrangements, particularly those involving legal procedures. Children are best served by arrangements that are reached by genuinely mutual consent and in a timely fashion. They may also benefit from arrangements that allow both parents to view themselves as "winners" in the conflict. Such resolutions can occur when parents are guided toward consensual agreements regarding their children's custody without adversarial legal action.

On balance, the economic and psychological well-being of children would be enhanced if information about divorce and its effects were widely disseminated and skilled mediation services were available to those parents who might be able to reach agreement when offered the opportunity and information to guide such discussions. Such mediation would be especially valuable when it is voluntarily sought by divorcing parents and when efforts are made 
to prohibit either partner from gaining an unfair advantage over the other. Various case management and arbitration services, as well as litigation, would of course remain available for the minority of couples in which intractable disagreements preclude such decision-making procedures. Educational programs focused on assisting parents and children to negotiate the process of divorce might also reduce some of the adverse effects of divorce.

\section{FURTHER RESEARCH}

Despite many years of careful research, there is much that remains to be learned about the effects of divorce and custody arrangements on children. Some of the most prominent lacunae are identified in this section.

Because most children are placed primarily in the physical custody of their mothers following divorce, most of the extant research has focused on children living with custodial mothers. As a result, we know relatively little about the psychosocial and economic circumstances of children living primarily with custodial fathers or in the joint physical custody of their two parents. Indeed, most of the existing research on joint physical custody involves families who voluntarily seek such a postdivorce arrangement, raising doubt concerning whether judicially imposed joint physical custody arrangements would offer similar benefits for the children involved. The lack of information about custodial fathers and joint custody arrangements significantly delimits the conclusions that can be offered about them.

The participants also agreed that we know very little about the postdivorce adjustment patterns of children and parents who are not White and reasonably affluent. To an embarrassing extent, the research reviewed in this document describes the status of more affluent White children, and the generalizability of those findings to children and parents from other backgrounds is unknown.

Finally, considerably greater information is needed about the factors predicting successful and unsuccessful postdivorce adjustment. As indicated earlier, for instance, we require much greater insight from studies of postdivorce custody and visitation to understand what typically occurs during visits between nonresidential parents and their offspring, what obstacles impede the success of their continuing relationships, and how continuing conflict between former spouses affects the success of visiting relationships. Moreover, researchers know much less about the processes contributing to psychosocial well-being in residential and nonresidential parents and their offspring than they do about the factors contributing to dysfunction and decline. As indicated earlier, for example, we must learn more about how children facing similarly difficult circumstances associated with their par- 
ents' divorces respond differently, with some succumbing to psychosocial dysfunction and poorer mental health while others seem unperturbed and even improve emotionally as a consequence. Quite likely, factors both within the family environment but also outside it (e.g., in sources of social support to children outside the home) are involved. It is likely that a better understanding of what constitutes "successful divorce" may contribute to more informed policy recommendations in the future.

Michael E. Lamb is head of the Section on Social and Emotional Development at the National Institute of Child Health and Human Development in Bethesda, MD. He was previously a professor of psychology, psychiatry, and pediatrics at the University of Utah.

Kathleen J. Sternberg (B.S.W., Ph.D., Hebrew University of Jerusalem) is a research psychologist and staff scientist at the National Institutes of Health in Bethesda, MD. Her research focuses on applied issues related to children's development.

Ross A. Thompson (M.S., Ph.D., University of Michigan) is a professor of psychology at the University of Nebraska, Lincoln. 